\title{
Flame retardancy of ethylene vinyl acetate (EVA) using new aluminum-based fillers
}

\author{
Roland El Hage, Amandine Viretto, Rodolphe Sonnier*, Laurent Ferry, \\ Jose-Marie Lopez-Cuesta
}

Centre C2MA, Ecole des Mines d'Alès, 6 Avenue de Clavières, F-30319 Alès Cedex, France

\begin{abstract}
A B S T R A C T
Flame retardancy of EVA copolymers using three new synthesized and two commercial hydrated mineral aluminum-based fillers having different aspect ratio was studied. It was shown that the peak of heat release rate (pHRR) in cone calorimeter test significantly decreased in presence of lamellar-shaped pseudoboehmites compared to that observed in presence of aluminum trihydroxyde and boehmite. On the opposite, thermogravimetric analysis (TGA) and Pyrolysis Combustion Flow Calorimeter analysis (PCFC) did not show any significant modification between the five formulations indicating that the pHRR decrease is related to barrier effect and not to endothermic effect or to improvement of thermal stability. No relationship was found between the pHRR decrease and the melt viscosity. ESEM and EDX analyses have confirmed that the efficiency of the barrier effect in presence of the two lamellar pseudoboehmites is assigned to migration phenomena of particles which led to the quick formation of a homogeneous and cohesive insulating layer.
\end{abstract}

Keywords:

Ethylene vinyl acetate

Pseudoboehmite

Flame retardancy

Filler migration

\section{Introduction}

Ethylene vinyl acetate (EVA) copolymer is widely used in numerous applications in biomedical, food industry, construction, transport, and electrical engineering areas such as drug delivery device [1], hot-melt adhesive [2], packaging [3] and essentially electric cable material [4], etc. However the high flammability of this polymer reduces its use for various applications. Thus, EVA must be protected using flame retardant (FR) agents. Various FR have been used to improve flame retardancy of EVA. Halogenated flame retardants (HFRs) have been extensively used over the past 40 years. Nevertheless, many studies reported by various authors indicate that HFRs exhibit health and environmental risks [5-7]. Moreover they lead to the production of halogenated dioxins and furans during combustion. For that purpose several HFRs have been restricted by the Stockholm Convention on persistent organic pollutants [8] and the use of halogenated compounds has started to be reduced in Europe. In the recent years, inorganic fillers (particularly precipitated aluminum trihydroxide) have been widely explored especially for EVA in wire and cable industry [4,9-11]. Among

\footnotetext{
* Corresponding author.

E-mail address: rodolphe.sonnier@mines-ales.fr (R. Sonnier).
}

other aluminum-based fillers, boehmite was used as flame retardant in various polymers (for example, polyethersulfone [12], polycarbonate/acrylonitrile-butadiene-styrene blends [13], poly(ethylene-terephtalate) [14], poly(methylmetacrylate) [15,16], poly(vinyl alcohol) [17]).

The thermal degradation of EVA and the modes-of-action of metallic hydroxides are well documented. EVA decomposes by a two steps mechanism, with the loss of acetic acid during the first step $\left(300-350{ }^{\circ} \mathrm{C}\right)$, resulting in the formation of unsaturated polyenes. The second decomposition step involves random chain scission of the remaining material, forming unsaturated vapor species $\left(\sim 430{ }^{\circ} \mathrm{C}\right)$, such as butene and ethylene [18]. Metallic hydroxides based on aluminum and magnesium are frequently used to improve the fire performance of EVA. They release water during heating through an endothermic decomposition which allows heat absorption and therefore polymer cooling. Water release leads to fuel dilution in vapor phase delaying ignition. In some cases, fillers also promote charring. Since high loadings of fillers must be used, the formation of an inert layer on the surface of decomposing polymer may improve flame retardancy through a so-called barrier effect [19]. Layer formation is assigned to various possible mechanisms. The main one is the ablation of polymer, which makes the surface richer in inorganic fillers [20]. Another one is related to fillers migration to the polymer surface during heat exposure [21]. 
Nevertheless it must be kept in mind that the accumulation of fillers at the surface is much more complex due to additional mechanisms including agglomeration, change in particle orientation, exfoliation induced by temperature and decomposition (in the case of montmorillonite) and bubbling [22,23].

Various authors have attempted to evaluate the migration phenomenon of nano-fillers by applying annealing or heating experiments at different temperatures under air or nitrogen conditions. The migration of the fillers upon heating was studied using various techniques: SEM, contact angle and surface free energy, AFM, ATR-FTIR, X-Ray diffraction, Raman, XPS and so on. Tang et al. [24] have evaluated the organomodified nano-clays migration versus annealing time and temperature. It results that migration occurs in the temperature range of $250-275^{\circ} \mathrm{C}$ and slows down for higher temperature and in presence of oxygen. Hao et al. [25] disclosed new evidence for clays migration in polypropylene upon heating $\left(200-250{ }^{\circ} \mathrm{C}\right)$ under air and under nitrogen. Using X-ray photoelectron spectroscopy the authors have confirmed the existence of clays migration phenomenon at relatively low temperatures due to surface composition changes. In a recent work, Isitman et al. [26] investigated the role of aluminum phosphinate nanoparticule geometry in flame retardancy of polylactide. The better fire performance was observed for the plate-like fillers and the authors proposed to correlate this observation to the extent and to the rate of migration of platelets on exposed samples surface. Various causes were suggested in the literature concerning the fillers migration phenomenon specifically for clay particles during directional and non-directional heating. It seems that gases and bubbling production during heating may play an important role by propelling the clay particles to the surface of EVA copolymer as suggested by Camino and coworkers [27]. Temperature and viscosity gradient formation with the increasing distance of samples from the heat source has a positive impact by accelerating the migration of the clay particles [28]. Difference in interfacial tension between the fillers and the matrix is also an important parameter that is directly related to fillers migration. Fillers having low surface tension and low cohesive energy with the matrix chains will be easily driven by migration phenomenon to the polymer surface during heat exposure [19]. Other studies have also explored the migration of nanoparticles using an annealing treatment [29-31].

The aim of the present study is to evaluate the effect of aluminum-based fillers migration in the reduction of the peak of heat release rate in cone calorimeter. To the best of our knowledge any evidence of migration of aluminum hydroxide mineral fillers has been reported in the literature. In this study, five inorganic fillers (25 wt.\%) with different geometries were used: two commercial grades of aluminum trihydroxyde (ATH) and aluminum monohydroxide (boehmite) and three developing grades of new inorganic fillers (two pseudoboehmites and one ATH) produced by Toyal Europe company. Thermal and flammability properties have been studied for these five formulations. Scanning Electron Microscopy (SEM) in combination with Energy Dispersive X-ray spectroscopy (EDX) was also used to draw a relation between fillers migration and flammability.

\section{Experimental}

\subsection{Materials}

The copolymer ethylene-co-vinyl acetate EVA Escorene ${ }^{\circledR}$ UL0026CC, Exxon, used in this study has a density of $0.949 \mathrm{~g} / \mathrm{cm}^{3}$, a melt flow index of $2 \mathrm{~g} / 10 \mathrm{~min}$ and a vinyl acetate content of $26 \mathrm{wt} . \%$. The two commercial grades of aluminum based fillers used are ground milled aluminum trihydroxyde (ATH-1: Martinal ${ }^{\circledR}$ ON313 Albemarle, 99.4\% purity), and precipitated boehmite (Boehm-1:
Nabaltec Apyral AOH20, 99\% purity). The three new grade fillers used are aluminum trihydroxyde (ATH-2) and two pseudoboehmites (Pseudo-1 and Pseudo-2) developed and supplied by Toyal Europe company. Designations and details of fillers characteristics (medium diameter D50 $(\mu \mathrm{m})$, density $\rho\left(\mathrm{g} / \mathrm{cm}^{3}\right)$, specific surface area SSA $\left(\mathrm{m}^{2} / \mathrm{g}\right)$, total pore volume $V_{\text {BET }}(\mathrm{ml} / \mathrm{g})$, mesopore diameter $\left.d_{\mathrm{h}(\mathrm{BJH})}(\mathrm{nm})\right)$ are summarized in Table 1 . For reasons of confidentiality the method of synthesis of the new aluminumbased fillers will not be revealed.

\subsection{Sample preparation}

Fillers were incorporated into the EVA matrix using a Haake Polylab internal mixer at $160{ }^{\circ} \mathrm{C}, 60 \mathrm{rpm}$ during $15 \mathrm{~min}$. The total loading level of fillers is $25 \mathrm{wt}$ \% for all the samples. Sheets of $100 \times 100 \times 4 \mathrm{~mm}^{3}$ were molded (100 bars, $160{ }^{\circ} \mathrm{C}$ and $10 \mathrm{~min}$ ) using a thermo-compression press Darragon. All the samples used for characterization were cut from these plates.

As discussed below, Pseudo-1 and Pseudo-2 exhibit low thermal stability. High amount of physisorbed water is released during melt-blending at $160{ }^{\circ} \mathrm{C}$. Therefore water release was no longer observed during compression molding. Plates for cone calorimeter tests have been obtained without porosity.

\subsection{Characterization and testing}

\subsubsection{Fillers characterizations}

The fillers porosity was determined from the nitrogen adsorption-desorption experiments using a Coulter SA 3100. The samples were outgassed at $130{ }^{\circ} \mathrm{C}$ for $24 \mathrm{~h}$ prior to their analysis. The specific surface areas (SSA, $\mathrm{m}^{2} / \mathrm{g}$ ) were calculated by the BET (Brunauer, Emmett and Teller) equation. The total pore volume $\left(V_{\mathrm{p}}\right.$, $\mathrm{ml} / \mathrm{g}$ ) was obtained using the maximum desorption at $\mathrm{P} / \mathrm{P}_{0}$ value of 0.9814 . The average mesopore diameter $\left(d_{\mathrm{h}}, \mathrm{nm}\right)$ was estimated using the BJH (Barrett, Joyner and Halenda) model applied to the desorption branches of the isotherms.

Densities $\left(\rho, \mathrm{g} / \mathrm{cm}^{3}\right)$ were determined using a Micromeritics AccuPyc SC1330 helium pycnometer after fillers drying at $130{ }^{\circ} \mathrm{C}$ and cooling in a desiccator at room temperature. Experimental values are then calculated from the average of 3 successive measurements on each sample.

The mean size distribution (D50, $\mu \mathrm{m}$ ) was carried out using a Beckman-Coulter light scattering particle size analyzer LS 230. The laser diffraction measurement was performed at room temperature using water as the suspension medium without any dispersion agent.

\subsection{Environmental scanning electron microscopy (ESEM)}

A Hitachi S-4300 environmental scanning electron microscope (ESEM) was used to observe fillers morphology. Aspect ratio (length/thickness, $L / t$ ) of primary particles was roughly evaluated from measurements of the length $L$ and the thickness $t$ of several particles. Fillers dispersion in the EVA matrix was also evaluated.

Table 1

Characteristics of the five aluminum-based fillers.

\begin{tabular}{|c|c|c|c|c|c|c|c|}
\hline $\begin{array}{l}\text { Alumina } \\
\text { fillers }\end{array}$ & Chemical formula & $\begin{array}{l}\text { SSA } \\
\left(\mathrm{m}^{2} / \mathrm{g}\right)\end{array}$ & $\begin{array}{l}\text { D50 } \\
(\mu \mathrm{m})\end{array}$ & $\rho\left(\mathrm{g} / \mathrm{cm}^{3}\right)$ & $\begin{array}{l}V_{\mathrm{p}} \\
(\mathrm{ml} / \mathrm{g})\end{array}$ & $\begin{array}{l}d_{\mathrm{h}} \\
(\mathrm{nm})\end{array}$ & $\begin{array}{l}\text { Aspect } \\
\text { ratio }\end{array}$ \\
\hline ATH-1 & $\mathrm{Al}(\mathrm{OH})_{3}$ & 1 & 13.7 & 2.45 & 0 & 0 & 3.8 \\
\hline ATH-2 & $\mathrm{Al}(\mathrm{OH})_{3}$ & 46 & 23.2 & 2.44 & 0.08 & 5.8 & 2.6 \\
\hline Pseudo-1 & $\mathrm{AlO}(\mathrm{OH}) 0.66 \mathrm{H}_{2} \mathrm{O}$ & 126 & 14.3 & 2.52 & 0.17 & 5.9 & 17 \\
\hline Pseudo-2 & $\mathrm{AlO}(\mathrm{OH}) 0.60 \mathrm{H}_{2} \mathrm{O}$ & 120 & 15.7 & 2.49 & 0.16 & 6.9 & 14 \\
\hline Boehm-1 & $\mathrm{AlO}(\mathrm{OH})$ & 2 & 7.0 & 3 & 0 & 0 & 2.8 \\
\hline
\end{tabular}


Small bars of EVA composites were frozen in liquid nitrogen and broken into two pieces and fractured surfaces were than examined.

\subsection{Cone calorimeter test}

Fire behavior was evaluated on $100 \times 100 \times 4 \mathrm{~mm}^{3}$ sheets according to ISO 5660 using a standard cone calorimeter manufactured by FTT. Specimens were burned horizontally on a balance in the presence of an igniter spark using incident heat flux of $50 \mathrm{~kW} /$ $\mathrm{m}^{2}$. The peak of heat release rate (pHRR), the time to ignition (TTI), the total heat release (THR), the residue content, the effective heat of combustion (EHC) and the combustion efficiency (calculated as the ratio between the effective heat of combustion and the effective heat of complete combustion measured in PCFC) were measured for EVA and EVA composites. All measurements were repeated three times and results were averaged.

\subsection{Pyrolysis combustion flow calorimeter analysis (PCFC)}

The samples were also studied using PCFC manufactured by FTT. 2-3 mg of samples were pyrolyzed by heating up to $750{ }^{\circ} \mathrm{C}$ at a heating rate of $1{ }^{\circ} \mathrm{C} / \mathrm{s}$ under a nitrogen flow. Gases released from samples pyrolysis are sent into a combustor and fully oxidized in presence of oxygen (20\%) at a temperature of $900{ }^{\circ} \mathrm{C}$. Each sample was analyzed at least 3 times. Average values of $\mathrm{pHRR}, T{ }^{\circ} \mathrm{C}_{\max }$ (temperature at pHRR) and THR, were then determined.

\subsection{Thermogravimetric analysis (TGA)}

Thermal stability of EVA, fillers and EVA composites was carried out on a Perkin-Elmer Pyris-1 thermal analysis system. Samples $(9 \pm 2 \mathrm{mg})$ were heated under nitrogen atmosphere $(20 \mathrm{ml} / \mathrm{min})$ in an alumina ceramic crucible from 20 to $800{ }^{\circ} \mathrm{C}$ at a heating rate of $10{ }^{\circ} \mathrm{C} / \mathrm{min}$.

\subsection{Differential scanning calorimetry (DSC)}

DSC analysis was used to evaluate the endothermic enthalpy associated to the mineral fillers decomposition [32]. All measurements were carried out with a Perkin-Elmer Diamond calorimeter, with $\sim 5 \mathrm{mg}$ of fillers encapsulated in a $50 \mu$ laluminum pan with holes to avoid an overpressure due to water release. External flexible vent tubing was attached to the purge cap of the cover kit to accelerate water venting to the outside environment. Experiments were carried out at least in duplicate from ambient to above the fillers decomposition temperature $\left(25-600{ }^{\circ} \mathrm{C}\right)$ under continuous flow of dry nitrogen gas $(50 \mathrm{ml} / \mathrm{min})$ at a heating rate of $10^{\circ} \mathrm{C} / \mathrm{min}$. The enthalpy of filler decomposition was calculated by the integration of all the endothermic peaks of DSC thermograms.

\subsection{Measurement of melt viscosity}

Complex melt viscosity of filled and pure EVA copolymers was measured using a TA-ARES (Advanced Rheometric Expansion System, Rheometric Scientific Co.) with parallel plates of $20 \mathrm{~mm}$ in diameter, under air atmosphere, an oscillation frequency of $0.1 \mathrm{rad} /$ $\mathrm{s}$ at $165{ }^{\circ} \mathrm{C}, 2 \%$ deformation and with a gap height of $2 \mathrm{~mm}$.

\subsection{Fillers migration evaluation}

Using the cone calorimeter, sheets of $30 \times 30 \times 4 \mathrm{~mm}^{3}$ of EVA composites were exposed to a heat flux of $50 \mathrm{~kW} / \mathrm{m}^{2}$ at different exposure time $(10,15,20,25,30,35 \mathrm{~s})$ before the ignition. An analytical balance (METTLER AT200) with an accuracy of $\pm 0.0001 \mathrm{~g}$ was used to follow the relative weight changes of the samples. Fillers migration was evaluated by monitoring the modification of the morphology of samples surface and cross section using ESEM. Using an OXFORD SDD $80 \mathrm{~mm}^{2}$ (Silicone Drive Detector) instrument, EDX (X-ray energy dispersion) quantitative analysis was also carried out to measure the superficial aluminum elementary percentage variation with the exposure time and the weight loss.

\section{Results and discussion}

\subsection{Fillers characterization}

ESEM micrographs show the different morphologies and shapes of mineral fillers used in this study in Fig. 1. The five mineral fillers exhibit different aspect ratio. ATH-1, ATH-2 and Boehm-1 consist of random platelet shape particles and rhomboedric aggregates, respectively with low aspect ratios (lower than 4). Pseudo-1 and Pseudo-2 exhibit a significant higher aspect ratio (14-17 corresponding to lamellar particles) which differs in the slices thickness. Pseudo- 1 consists of thinner lamellar particles $(0.3-0.4 \mu \mathrm{m})$ than Pseudo-2 $(0.7-0.8 \mu \mathrm{m})$. Data in Table 1 show higher specific surface area for Pseudo-1 and Pseudo-2 and at a lesser degree for ATH-2. The main difference between the five fillers is the porous structure of the new developed aluminum based fillers exhibiting an average mesopore diameter $\left(d_{\mathrm{h}}\right)$ of $6-7 \mathrm{~nm}$ and a total pore volume $\left(V_{\mathrm{p}}\right)$ of $0.169,0.155,0.077 \mathrm{ml} / \mathrm{g}$ for Pseudo-1, Pseudo-2 and ATH-2 respectively. The estimated density fits well with literature values and is slightly higher for Boehm-1 and very similar for the others. ATH-1, Pseudo-1 and Pseudo-2 have very close medium size (D50) of $14-15 \mu \mathrm{m}$, ATH-2 is constituted by large agglomerates with medium size (D50) of $23.2 \mu \mathrm{m}$ and boehm-1 particles exhibit the smallest medium size of about $7 \mu \mathrm{m}$.

Pseudo-1 and Pseudo-2 decompose over a wider temperature range than the other fillers due to their highly porous structure as observed by the TGA-DTG curves (Fig. 2). The DTG curves show the presence of two peaks of mass loss rate. The first peak is observed for a temperature below $100{ }^{\circ} \mathrm{C}$ (about $50-60{ }^{\circ} \mathrm{C}$ ) corresponding to the release of physisorbed water in mesopores. A second large peak observed above $100{ }^{\circ} \mathrm{C}$ (from $120^{\circ} \mathrm{C}$ to $480^{\circ} \mathrm{C}$ ) is attributed to the release of the remaining water physisorbed in micropores and to structural water. The total weight loss is about $28-29 \%$ corresponding to $13 \%$ of physisorbed water and $16 \%$ of structural water (Additional experiments - data not shown - were carried out to estimate the respective fractions of physisorbed and structural water). This behavior is in agreement with literature results showing that pseudoboehmites start losing physisorbed water from ambient to $200{ }^{\circ} \mathrm{C}$ [33]. It is noticeable that water release of the two pseudoboehmites occurs gradually before and after the beginning of the degradation of EVA copolymer. The thermal decomposition varies depending on the chemical composition of the different investigated samples. ATH-1 and ATH-2 thermal degradation seems to be quite similar with one difference concerning the onset of weight loss of ATH-2 at $100{ }^{\circ} \mathrm{C}$ corresponding to the desorption of $1 \%$ of physisorbed water. ATH- 1 and ATH-2 total dehydration occurs at $290{ }^{\circ} \mathrm{C}$ and $273{ }^{\circ} \mathrm{C}$ respectively by losing $35 \%$ and $33 \%$ of their total weight before the beginning of EVA copolymer degradation. Boehm-1 shows a quite distinct behavior from the other mineral fillers. A total weight loss of $17 \%$ is observed around $535{ }^{\circ} \mathrm{C}$ corresponding to the release of structural water. The dehydration process of boehmite partially occurs during the main degradation step of the EVA copolymer.

The endothermic energy related to the decomposition of the different fillers was estimated by DSC analysis. Results are reported in Table 2. Similar behavior is observed for the two pseudoboehmites (Pseudo-1 and Pseudo-2). A weak endothermic peak 

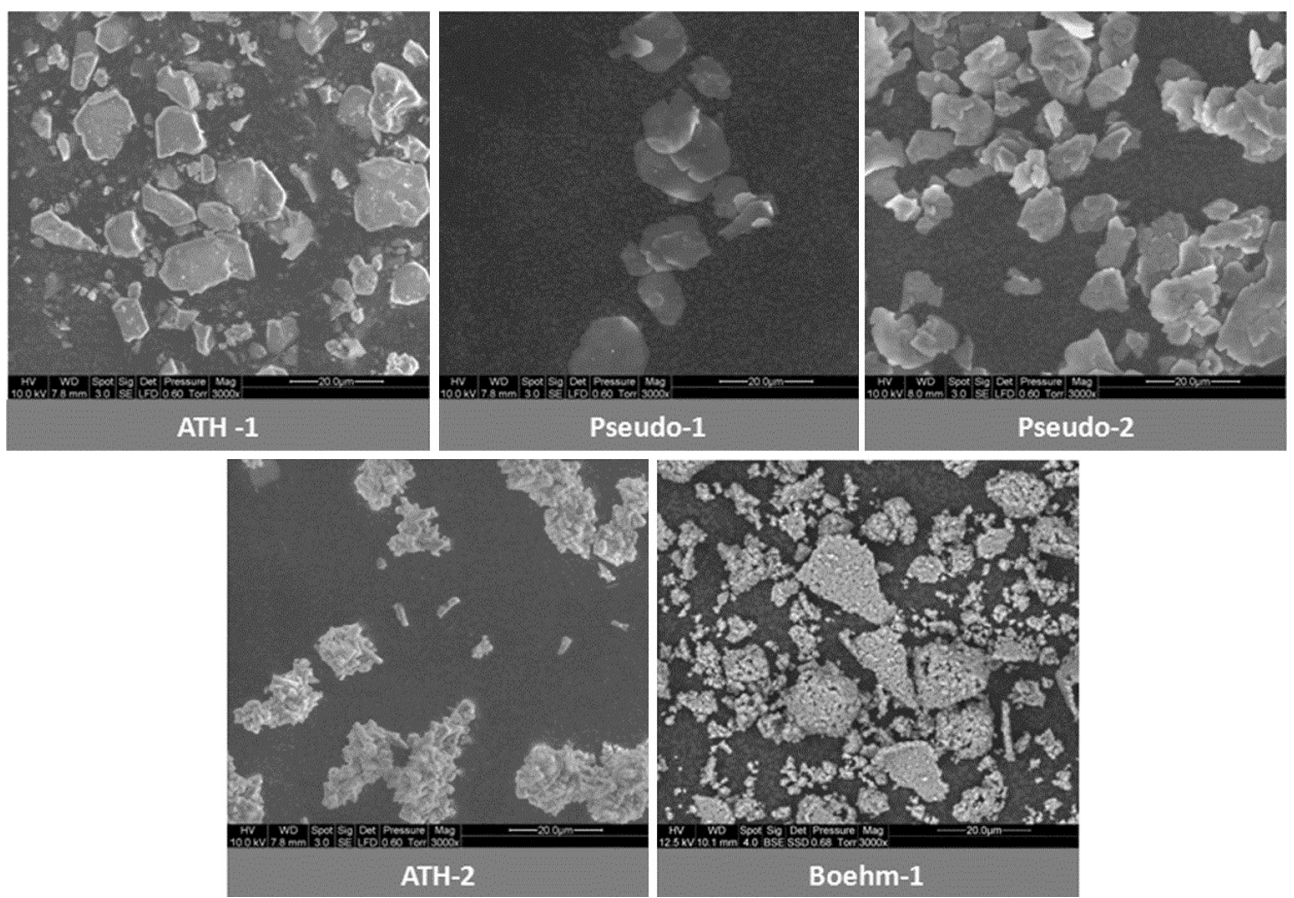

Fig. 1. ESEM image of fillers.

was observed between 30 and $180{ }^{\circ} \mathrm{C}$ corresponding to the release of physisorbed water. A second endothermic peak was observed between 300 and $480{ }^{\circ} \mathrm{C}$ corresponding to the total conversion of pseudoboehmite into alumina oxide [34]. Two endothermic peaks at different temperatures were also observed for ATH-1, ATH-2 and Boehm-1 corresponding to the release of structural water. The quantification of the endothermic effect is achieved by determining the total enthalpy change from the peak area for the different samples (Table 2). Endothermic enthalpy for the five fillers is classified as mentioned below:

ATH-1 > ATH-2 > Boehm-1 > Pseudo-1 > Pseudo-2 $1156 \mathrm{~J} / \mathrm{g}>1050 \mathrm{~J} / \mathrm{g}>599 \mathrm{~J} / \mathrm{g}>477 \mathrm{~J} / \mathrm{g}>372 \mathrm{~J} / \mathrm{g}$.
This ranking shows that the decomposition of ATH-1 and ATH-2 induces a higher endothermic effect than the other fillers. However, the endothermic effect depends not only on the energy consumed by the decomposition of the fillers but also on the temperature range in which this decomposition occurs. Hence, aluminum hydroxide fillers (ATH-1 and ATH-2) should potentially act endothermically by heat absorption keeping the surrounding polymer cooler and by the release of high amount of diluent water (inert gas), boehmite decomposes mainly after EVA degradation and endothermic enthalpy corresponding to pseudoboehmites decomposition is quite low. Therefore these fillers (Pseudoboehmite and boehmite) should exhibit a relative inefficient endothermic effect.
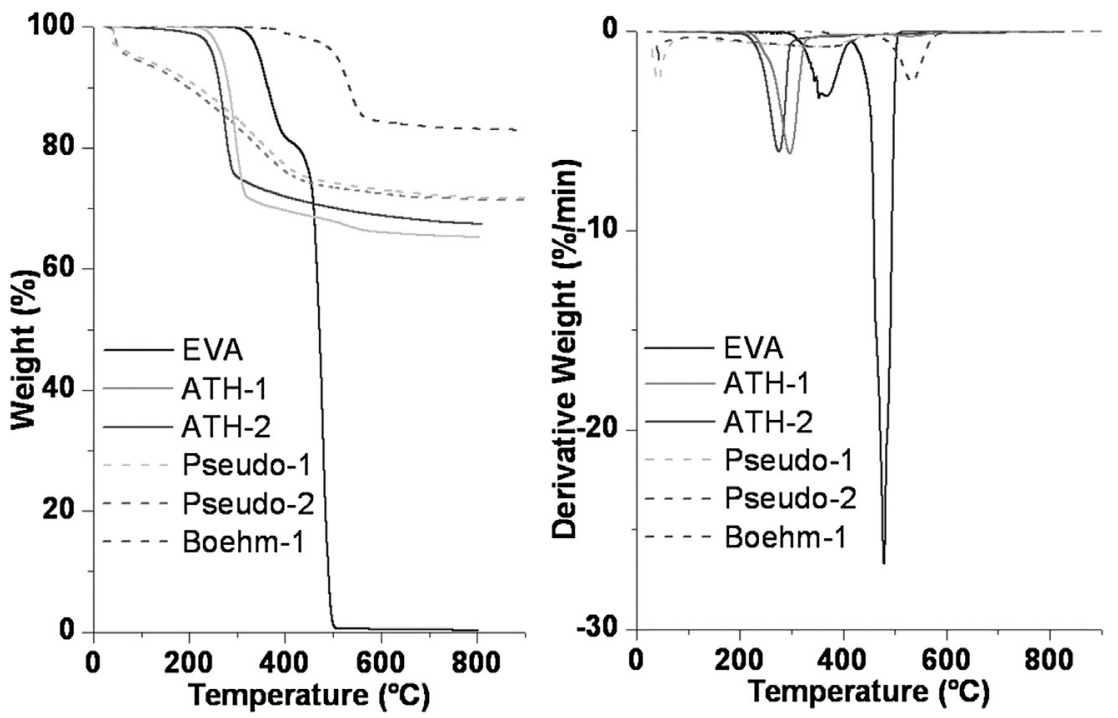

Fig. 2. TGA and DTG curves of pure EVA and various mineral fillers. 
Table 2

Mean enthalpy change $(\Delta H)$ of fillers.

\begin{tabular}{lllr}
\hline & Temperature range $\left({ }^{\circ} \mathrm{C}\right)$ & Peak temperature $\left({ }^{\circ} \mathrm{C}\right)$ & $\Delta H(\mathrm{~J} / \mathrm{g})$ \\
\hline ATH-1 & $225-260$ & 240 & 45 \\
& $280-330$ & 318 & 1111 \\
ATH-2 & $260-315$ & Total & $\mathbf{1 1 5 6}$ \\
& $340-460$ & 296 & 1014 \\
& & 415 & 36 \\
Pseudo-1 & $30-180$ & Total & $\mathbf{1 0 5 0}$ \\
& $300-480$ & 88 & 91 \\
Pseudo-2 & $30-180$ & 415 & 386 \\
& $300-480$ & Total & $\mathbf{4 7 7}$ \\
& & 96 & 25 \\
Boehm-1 & $150-260$ & 420 & 372 \\
& $500-560$ & Total & $\mathbf{3 9 7}$ \\
& & 200 & 78 \\
& & 536 & 521 \\
& & Total & $\mathbf{5 9 9}$ \\
\hline
\end{tabular}

\subsection{EVA composites characterization}

\subsubsection{Cone calorimetry}

The fire behavior of pure EVA and EVA/fillers (75/25) composites was studied using the cone calorimeter with an incident heat flux of $50 \mathrm{~kW} / \mathrm{m}^{2}$. Fig. 3 shows the heat release rate (HRR) and weight loss versus time and Table 3 summarizes the main data obtained for the different formulations. Virgin EVA burns completely without charring. Note that ignition was significantly delayed in the presence of Boehm-1 while other fillers did not modify significantly the time to ignition. The highest peak HRR is observed in the presence of the two aluminum trihydroxyde (ATH-1 and ATH-2) despite the existence of a higher specific surface area and a porous structure for ATH-2. A significant decrease of the pHRR is observed in presence of the two pseudoboehmites (Pseudo-1 and Pseudo-2). The boehmite exhibits an intermediate pHRR. The same tendency is also visible from the weight loss curves as seen in Fig. 3-b. The lowest weight loss rate is observed for formulations containing $25 \%$ of Pseudo-1, Pseudo-2 and boehm-1.

Calculated residue was obtained considering only alumina (from the decomposition of the fillers) without any charring from EVA. Char yield was calculated as the difference between the experimental residue and the calculated one. As seen in Table 3, no char was detected for ATH-containing EVA. A small amount of char is observed for boehmite and pseudoboehmites. Nevertheless, this effect is very weak and no significant difference was observed for the total heat release (THR) between the composites. However the THR of the composites are lower than that of virgin EVA because of a dilution effect (replacement of polymer by fillers).

Effective heat of combustion (EHC) is in the same range $(22-24 \mathrm{~kJ} / \mathrm{g})$ for all composites because the entire polymer was degraded. EHC is slightly lower than the value for pure EVA $(26 \mathrm{~kJ} /$ g) due to the water release from fillers.

The combustion efficiency $(\chi)$ corresponds to the ratio of EHC obtained by cone calorimeter and the EHC obtained by PCFC and TGA (determined below). It seems that the $\chi$ values are the same for all the formulations (around 0.7). The combustion is not complete in cone calorimeter even for pure EVA and the fillers studied do not exhibit any flame inhibition effect.

These results indicate that Pseudo-1 and Pseudo-2 are more efficient to enhance the flame retardancy of EVA, and particularly to reduce the peak of heat release rate. Fillers efficiency is evaluated as follows: ATH- $1<$ ATH- 2 < Boehm- $1<$ Pseudo- 2 Pseudo- 1 which corresponds to a pHRR decrease (relatively to virgin EVA) of $39 \%<48 \%<55 \%<62 \%-66 \%$ respectively. In the following, supplementary investigations are done to explain the high efficiency of pseudoboehmites as flame retardant.

Fig. 4 shows pictures of sample residues obtained after the cone calorimeter test for the different formulations. Fig. 4-a shows the formation of a non-cohesive and non-charred residue for the EVA/ ATH-1 (75/25) formulation. It is remarkable that the residue does not cover the surface and is located mainly on the edges of the sample holder. Better surface coverage is observed for residue of ATH-2 composites (Fig. 4-b). However, the formed residue is weakly cohesive and shows almost no trace of char. In the presence of boehmite (Boehm-1), the residue covers the entire surface and the formation of a black char is observed (Fig. 4-c). The two pseudoboehmites (Pseudo-1 and Pseudo-2) seem to exhibit a slightly inflated and highly cohesive residues with traces of char (Fig. 4$\mathrm{d}$ and -e). For the last three fillers, the residue aspect (evidences of charring) is well correlated with the char yield calculated in Table 3. These observations allow assuming that the lowest values of pHRR obtained in presence of Pseudo- 1 and Pseudo-2 are strongly related to barrier effect.
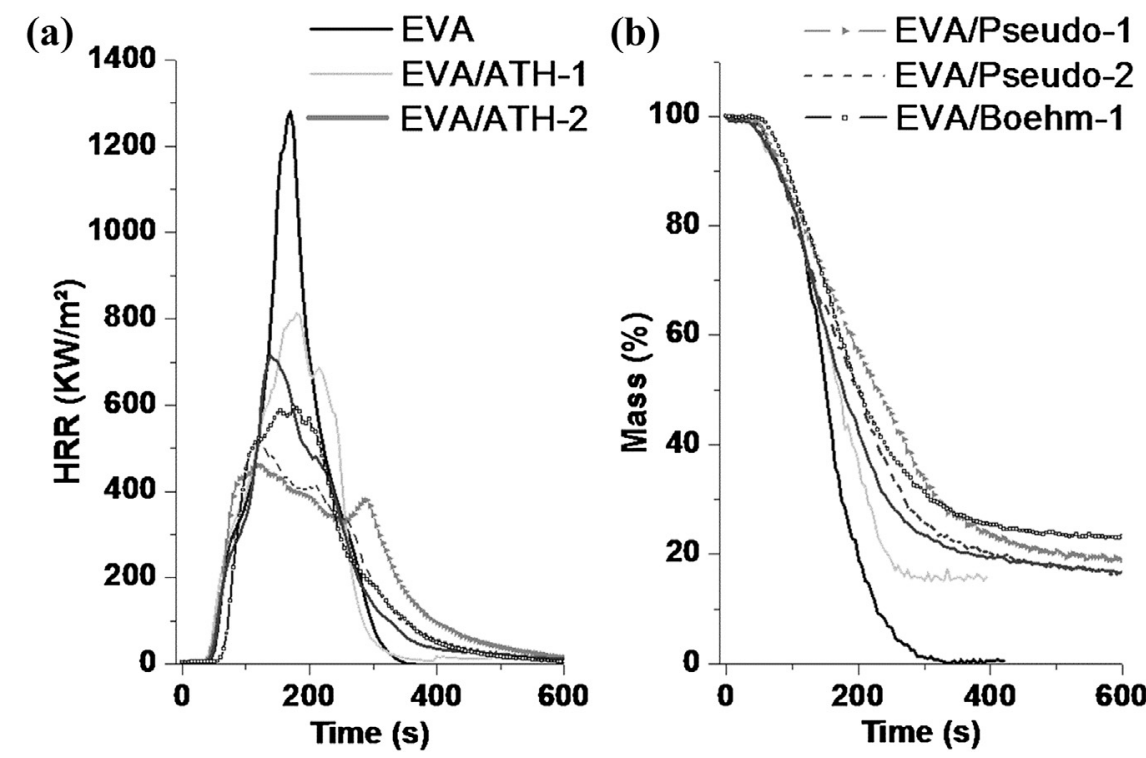

Fig. 3. Cone calorimeter (a) heat release rate $\left(\mathrm{KW} / \mathrm{m}^{2}\right)$ and (b) mass (\%) curves of EVA and EVA composites. 
Table 3

Cone calorimeter data for EVA and EVA composites.

\begin{tabular}{|c|c|c|c|c|c|c|c|c|}
\hline Formulations & $\mathrm{pHRR}\left(\mathrm{kW} / \mathrm{m}^{2}\right)$ & $\mathrm{EHC}\left(\mathrm{KJ} \mathrm{g}^{-1}\right)$ & $\operatorname{THR}\left(\mathrm{MJ} / \mathrm{m}^{2}\right)$ & TTI (s) & Experimental residue (\%) & Calculated residue (\%) & Char yield (\%) & $\chi$ \\
\hline EVA & $1366 \pm 133$ & $26 \pm 1$ & $135 \pm 1$ & $39 \pm 5$ & 0.0 & 0.0 & 0.0 & 0.73 \\
\hline EVA/ATH1 & $833 \pm 24$ & $22 \pm 4$ & $123 \pm 2$ & $34 \pm 3$ & $16.3 \pm 0.5$ & $16 \pm 0.2$ & $0.6 \pm 0.4$ & 0.70 \\
\hline EVA/ATH-2 & $710 \pm 53$ & $23 \pm 2$ & $121 \pm 5$ & $37 \pm 2$ & $17.2 \pm 0.8$ & $17 \pm 0.1$ & $0.5 \pm 0.2$ & 0.69 \\
\hline EVA/Pseudo-1 & $460 \pm 15$ & $22 \pm 2$ & $116 \pm 4$ & $36 \pm 5$ & $20 \pm 0.1$ & $18 \pm 0.4$ & $2 \pm 0.4$ & 0.68 \\
\hline EVA/Pseudo-2 & $522 \pm 1$ & $24 \pm 4$ & $114 \pm 5$ & $39 \pm 2$ & $21 \pm 0.4$ & $18 \pm 0.3$ & $3 \pm 0.6$ & 0.72 \\
\hline EVA/Boehm-1 & $612 \pm 2$ & $24 \pm 3$ & $122 \pm 3$ & $54 \pm 8$ & $23 \pm 0.2$ & $21 \pm 0.1$ & $2 \pm 0.3$ & 0.72 \\
\hline
\end{tabular}

\subsubsection{Pyrolysis combustion flow calorimeter analysis (PCFC)}

The heat release rate (HRR) curves versus temperature of EVA and EVA composites are shown in Fig. 5. Table 4 summarizes the values of pHRR $(\mathrm{W} / \mathrm{g})$, maximum degradation temperature $\left(T_{\max }\right)$ and THR $(\mathrm{kJ} / \mathrm{g})$.

Virgin EVA and EVA composites exhibit two heat release rate peaks around $370{ }^{\circ} \mathrm{C}$ and $485^{\circ} \mathrm{C}$ which corresponds to the polymer deacetylation and to the degradation of the ethylene units and the polyene backbone respectively [35]. A slight increase of the maximum degradation temperature is observed for all the EVA composites in comparison with the virgin EVA. The pHRR and THR of all the EVA composites exhibit the same trend (decrease of about $25 \%$ compared to virgin EVA due to dilution effect) except for the mixture containing boehmite where the pHRR and THR values are slightly lower.

To determine the main mode-of-action of mineral fillers, an evaluation was carried out by combining the results obtained with the cone calorimeter and the PCFC. This method was reported by Sonnier et al. [36]. Fig. 6 shows the evolution of R1 (Y-axis) versus $\mathrm{R} 2$ ( $X$-axis) where $\mathrm{R} 1$ is the ratio between Heat Release Capacity (HRC) in PCFC of the flame-retarded polymer and HRC in PCFC of the virgin polymer and $\mathrm{R} 2$ is the ratio of pHRR in cone calorimeter for the flame-retarded polymer and the pHRR in cone calorimeter of the virgin polymer. Heat release capacity is equal to the pHRR divided by the heating rate $(1 \mathrm{~K} / \mathrm{s})$. As observed in Fig. 7, all formulations are above the dotted line $\mathrm{R} 1=\mathrm{R} 2$ (which corresponds to similar decrease of pHRR in cone calorimeter and of HRC in PCFC). It means that the decrease of pHRR in cone calorimeter is higher than the decrease of HRC in PCFC. This tendency indicates that the main mode-of-action of the studied flame retardants is the barrier effect. The most efficient barrier effect corresponds to formulations which are the most distant from the R1 = R2 curve. The lowest barrier effect is obtained in presence of the aluminum trihydroxyde (ATH-1 and $\mathrm{ATH}-2$ ) while the most efficient barrier effect is obtained in presence of the new pseudoboehmites (Pseudo-1 and Pseudo-2).

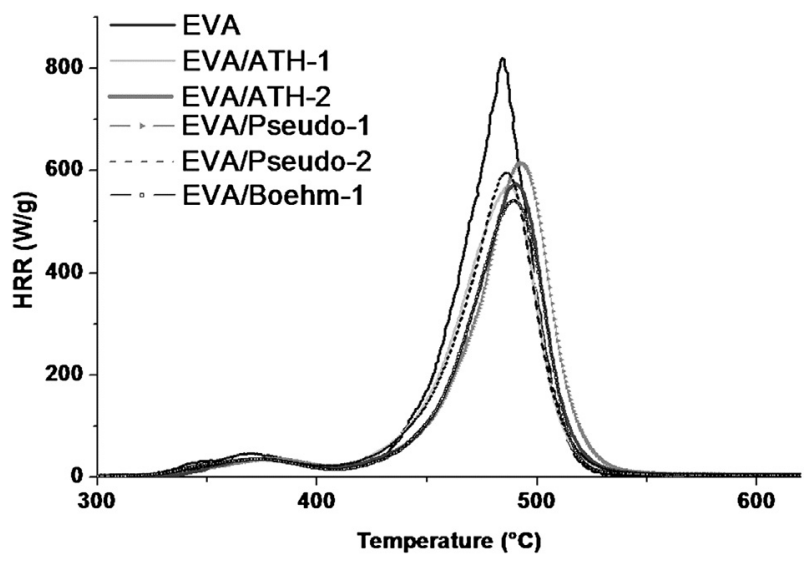

Fig. 5. PCFC heat release curves of EVA and EVA composites.
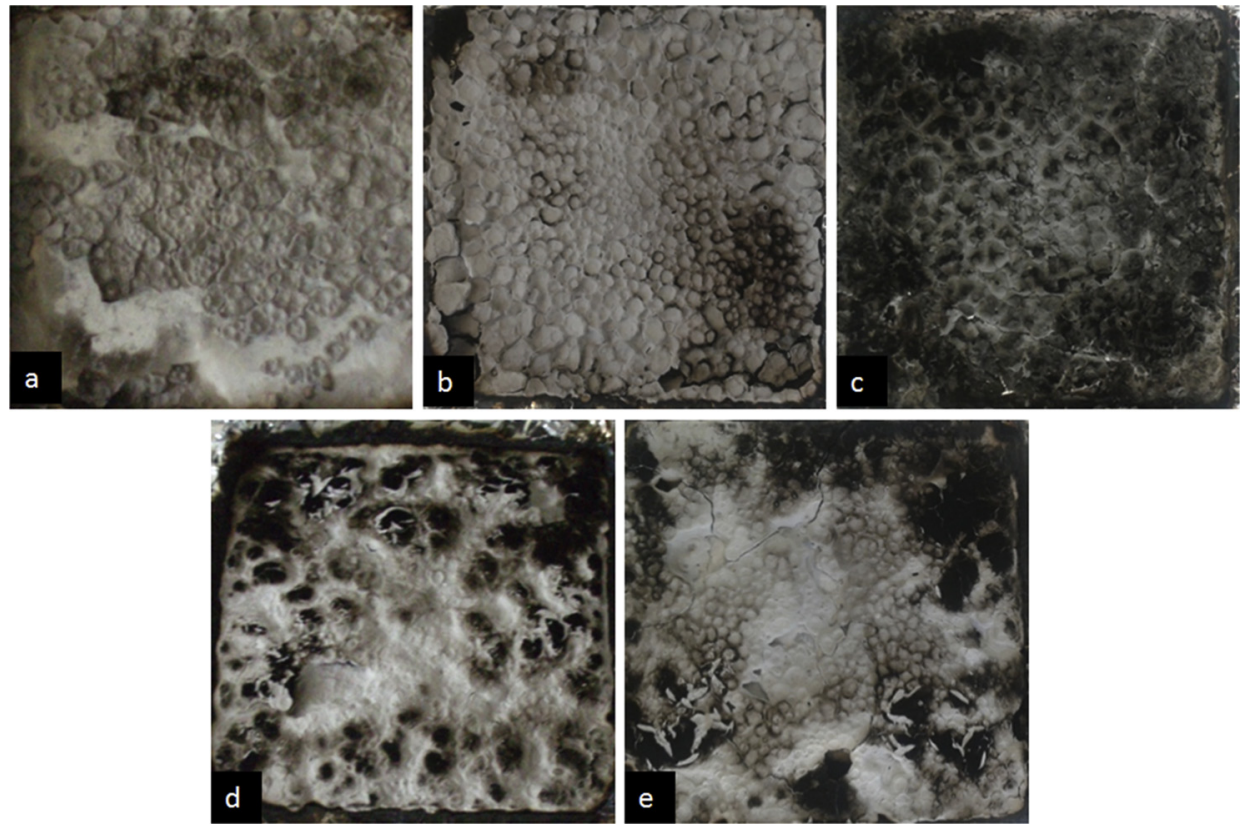

Fig. 4. Pictures of residues after cone calorimeter tests on EVA composites: a) ATH1, b) ATH2, c) Boehm-1, d) Pseudo-1, e) Pseudo-2. 
Table 4

PCFC results for EVA and EVA composites.

\begin{tabular}{llll}
\hline Samples & pHRR $(\mathrm{W} / \mathrm{g})$ & $T$ Max $\left({ }^{\circ} \mathrm{C}\right)$ & THR $(\mathrm{kJ} / \mathrm{g})$ \\
\hline EVA & $800 \pm 15$ & $490 \pm 4$ & $34.8 \pm 0.2$ \\
EVA/ATH-1 & $567 \pm 4$ & $487 \pm 2$ & $27.7 \pm 0.3$ \\
EVA/ATH-2 & $572 \pm 4$ & $490 \pm 1$ & $27.0 \pm 1.0$ \\
EVA/Pseudo-1 & $612 \pm 15$ & $492 \pm 2$ & $28.1 \pm 0.6$ \\
EVA/Pseudo-2 & $593 \pm 9$ & $485 \pm 3$ & $27.4 \pm 0.4$ \\
EVA/Boehm-1 & $538 \pm 5$ & $489 \pm 1$ & $25.5 \pm 0.3$ \\
\hline
\end{tabular}

Table 5

TGA-DTG results for EVA and EVA composites.

\begin{tabular}{llllc}
\hline Formulations & $\mathrm{T} \mathrm{Max}\left({ }^{\circ} \mathrm{C}\right)$ & $\begin{array}{l}\text { Maximal mass } \\
\text { loss rate }(\% / \mathrm{min})\end{array}$ & $\begin{array}{l}\text { Residue }(\%) \\
\left(800{ }^{\circ} \mathrm{C}\right)\end{array}$ & $\begin{array}{l}\text { Calculated } \\
\text { residue }(\%)\end{array}$ \\
\hline EVA & 478 & 26 & 0 & 0 \\
EVA/ATH-1 & 483 & 16.4 & 16.7 & 16.3 \\
EVA/ATH-2 & 484 & 17.4 & 17.0 & 16.9 \\
EVA/Pseudo-1 & 483 & 16.8 & 17.3 & 17.8 \\
EVA/Pseudo-2 & 485 & 17.4 & 18.8 & 18 \\
EVA/Boehm-1 & 481 & 15.7 & 24 & 21 \\
\hline
\end{tabular}

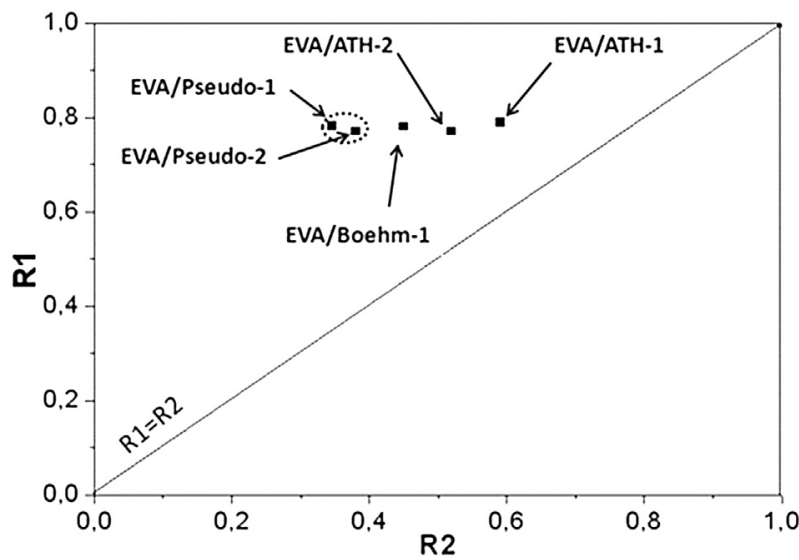

Fig. 6. R1 versus R2 of the five composites (EVA/fillers - 75/25).
Table 6

Melt complex viscosity $\left(\eta^{*}\right)$ of EVA and EVA composites measured at $165^{\circ} \mathrm{C}$ and a frequency of $0.1 \mathrm{rad} / \mathrm{s}$.

\begin{tabular}{ll}
\hline Frequency $=0.1 \mathrm{rad} / \mathrm{s}$ & \\
\hline Formulations & $\eta^{*}($ Pa s $)$ \\
\hline EVA & $17,000 \pm 470$ \\
EVA/ATH2 & $26,300 \pm 680$ \\
EVA/ATH1 & $23,300 \pm 180$ \\
EVA/Pseudo-1 & $29,300 \pm 810$ \\
EVA/Pseudo-2 & $21,400 \pm 260$ \\
EVA/Boehm-1 & $24,800 \pm 490$ \\
\hline
\end{tabular}

\subsubsection{Thermogravimetric analysis (TGA)}

The TGA-DTG curves of virgin EVA and EVA composites are shown Fig. 7. Table 5 summarizes the results of the maximum degradation temperature, the percentage of experimental residue obtained at $800{ }^{\circ} \mathrm{C}$, the percentage of calculated residue and the char yield (calculated as the difference between the experimental value and the calculated one). As observed in PCFC analysis, virgin EVA is characterized by a two-steps decomposition (deacetylation and polyene degradation) around $371{ }^{\circ} \mathrm{C}$ and $479{ }^{\circ} \mathrm{C}$ respectively. Small peaks are detected in presence of ATH- 1 and ATH-2 between $268{ }^{\circ} \mathrm{C}$ and $323^{\circ} \mathrm{C}$ corresponding to the fillers dehydration process (water release before deacetylation). The same observation is detected for boehmite at higher temperature showing the release of water around $523{ }^{\circ} \mathrm{C}$ after the EVA degradation. From a general point of view, the TGA-DTG results show no significant difference between the different formulations of EVA loaded with $25 \mathrm{wt} . \%$ of fillers. No shift of temperature of the main degradation step is observed for the composites. The only remarkable point is observed in presence of boehmite which caused slightly higher charring for EVA with a char yield of 3\%. This observation explains the lowest value of THR and PHRR at PCFC observed previously due to incomplete degradation of the EVA copolymer. These results also confirm that the pseudoboehmites do not enhance the thermal stability of EVA.

\subsubsection{Measurement of melt viscosity $\left(\eta^{*}\right)$}

Several studies in the literature have attempted to correlate flammability properties (e.g. mass loss rate and pHRR) to
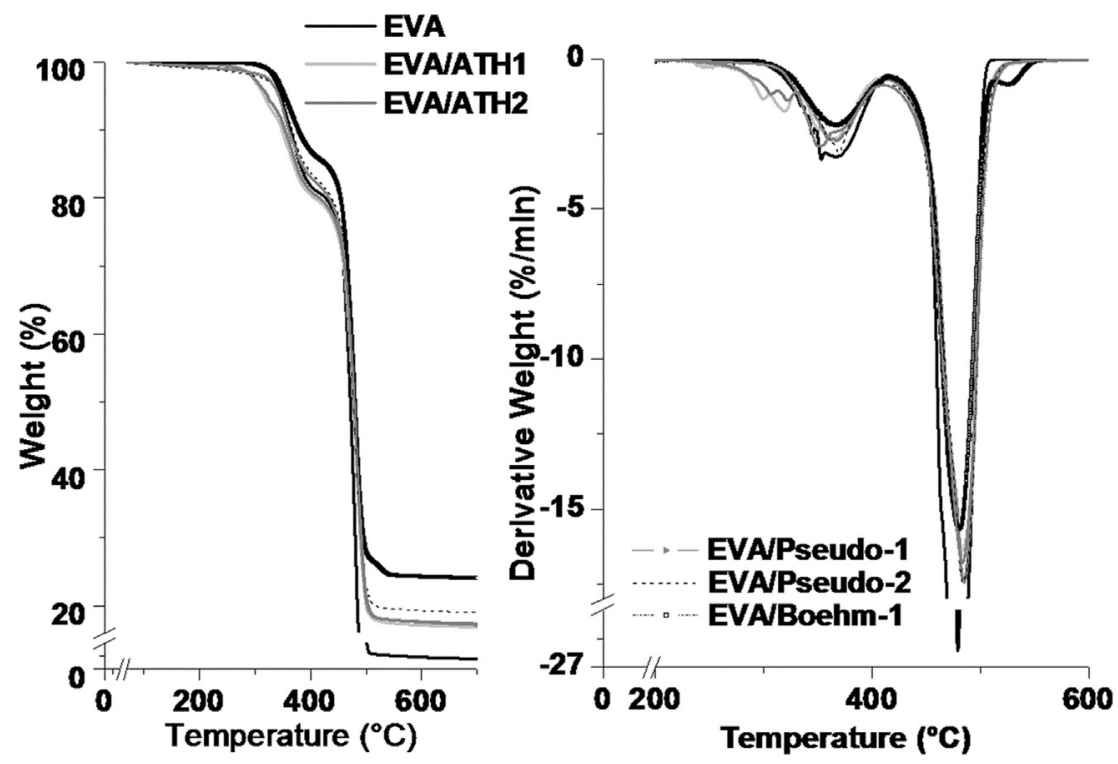

Fig. 7. TGA and DTG curves of pure EVA and various filled EVA composites. 

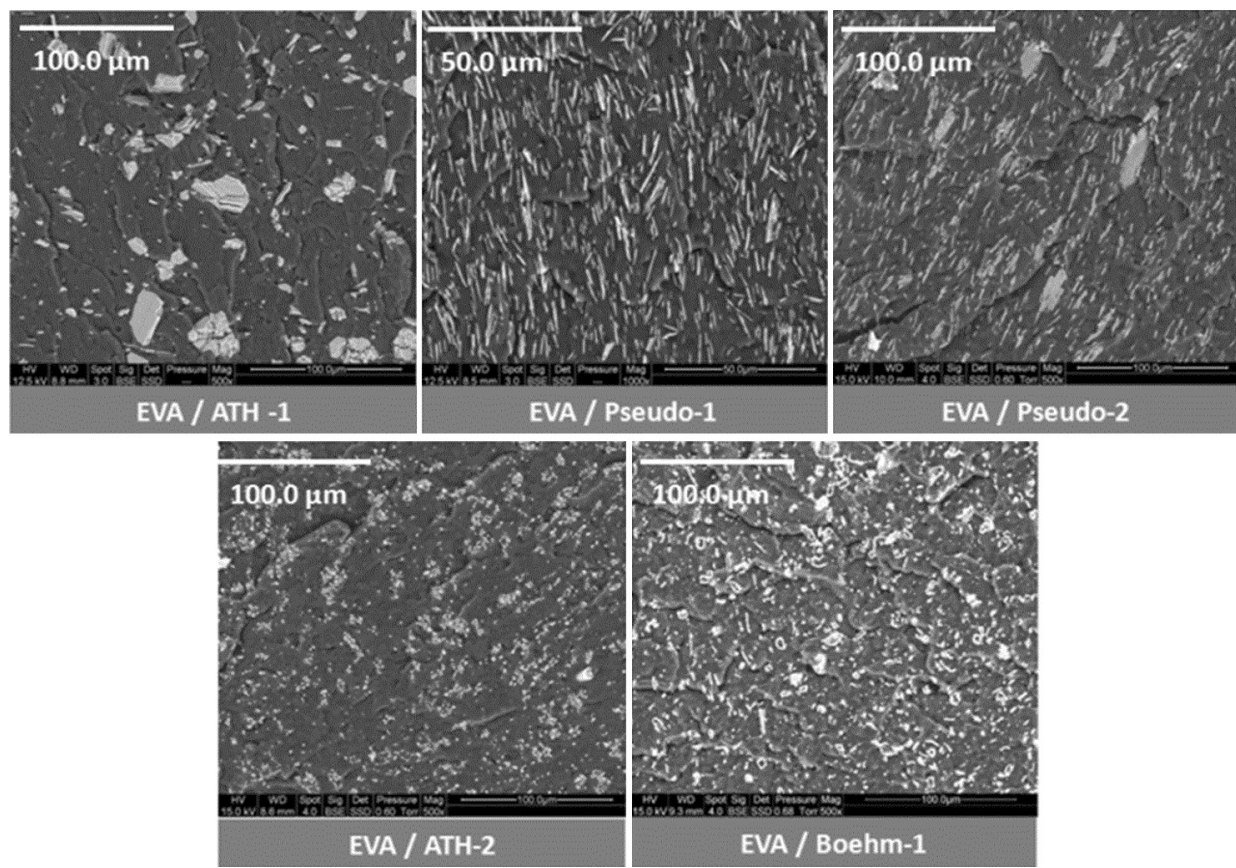

Fig. 8. Cross section ESEM micrographs of 25\% fillers dispersion in EVA copolymer.

rheological analysis. Kashiwagi et al. [37] have established a relationship between damping parameter $(\tan \delta$ ) determined in the molten state and the degradation rate of polystyrene filled with clays. They showed that the degradation rate decreased when the polymer damping decreased. Other works [38] have shown that the melt viscosity of poly(methyl methacrylate) increased with loading of $10 \%$ of highly surface area and porous silica leading to significant positive effects on flammability properties. In the present work the melt viscosity of virgin EVA and EVA composites measured at $165^{\circ} \mathrm{C}$ and at a frequency of $0.1 \mathrm{rad} / \mathrm{s}$ is shown in Table 6. It should

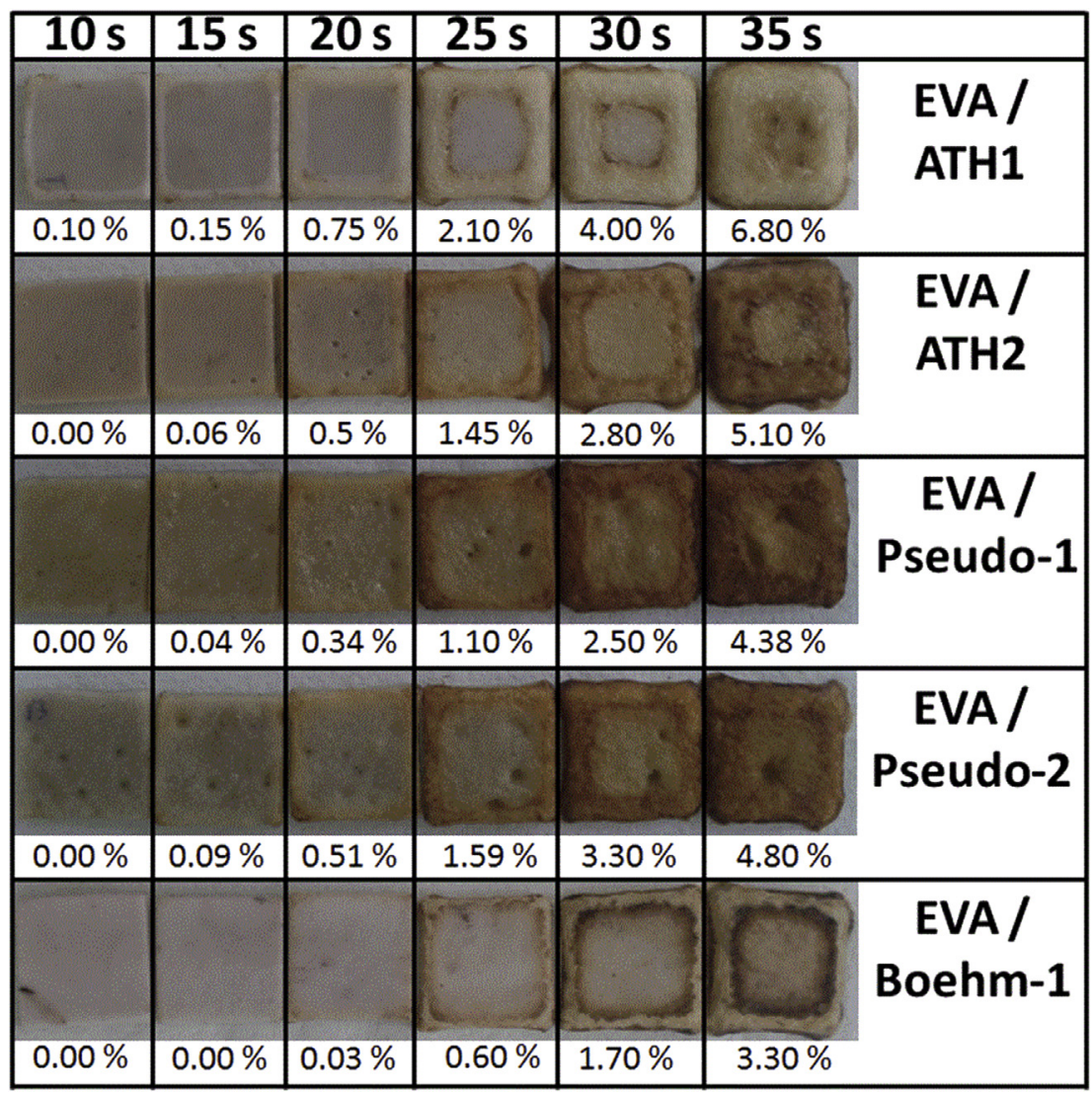

Fig. 9. Photographs of EVA composites surface after heat exposure at different exposure times; Percentage values correspond to sample weight loss after each exposure time. 
be noted that the two formulations with Pseudo-1 and Pseudo-2 which previously showed the best flammability properties (i.e. the lowest pHRR in cone calorimeter test) exhibit the highest and the lowest melt viscosities respectively. These results lead us to assume that the melt viscosity does not control the flame retardancy of the composites in cone calorimeter test.

\subsubsection{ESEM observations of EVA composites}

ESEM observations were carried out on the cross sections of the five EVA composites in order to evaluate the fillers dispersion. Results are presented Fig. 8. ATH-1, Pseudo- 1 and Pseudo-2 are well dispersed in the EVA matrix. Boehm-1 and ATH-2 are dispersed homogeneously as aggregated particles in the EVA matrix. A remarkable point should be highlighted concerning the Pseudo-1 and the Pseudo- 2 fillers arrangement. Both fillers exhibit a preferential orientation parallel to the surface of the samples. The orientation is slightly disturbed in presence of Pseudo-2. It is suggested that this specific orientation contributes to a very efficient barrier effect as observed from cone calorimeter tests.

\subsubsection{Study of fillers migration}

Photos of pure EVA and EVA composites samples as well as the weight loss (\%) after 10,15, 20, 25, 30 and $35 \mathrm{~s}$ of exposure to heat flux of $50 \mathrm{~kW} / \mathrm{m}^{2}$ in cone calorimeter (before ignition) are presented Fig. 9. EVA containing ATH-1 starts melting from $10 \mathrm{~s}$ of exposure. For the other formulations the beginning of surface melting starts at about $25 \mathrm{~s}$. The color darkening is assigned to the beginning of EVA degradation. The weight loss (\%) presented in Fig. 9 increases with time exposure for all the formulations. It is noteworthy that the weight loss is faster in presence of ATH- 1 and lower in presence of boehmite (Boehm-1). The weight loss in presence of Pseudo-1, Pseudo-2, and ATH-2 are substantially similar and corresponds to intermediate values.

ESEM images $(\times 100)$ of the upper surface and the lower surface after heat exposure are shown in Fig. 10. No modification of the upper and lower surfaces is detected after $10 \mathrm{~s}$ of exposure time for all EVA composites. At $15 \mathrm{~s}$ a change is observed on the upper surface of EVA/Pseudo-1 composite reflecting the formation of a white crust. At $20 \mathrm{~s}$ the same phenomenon is observed for EVA
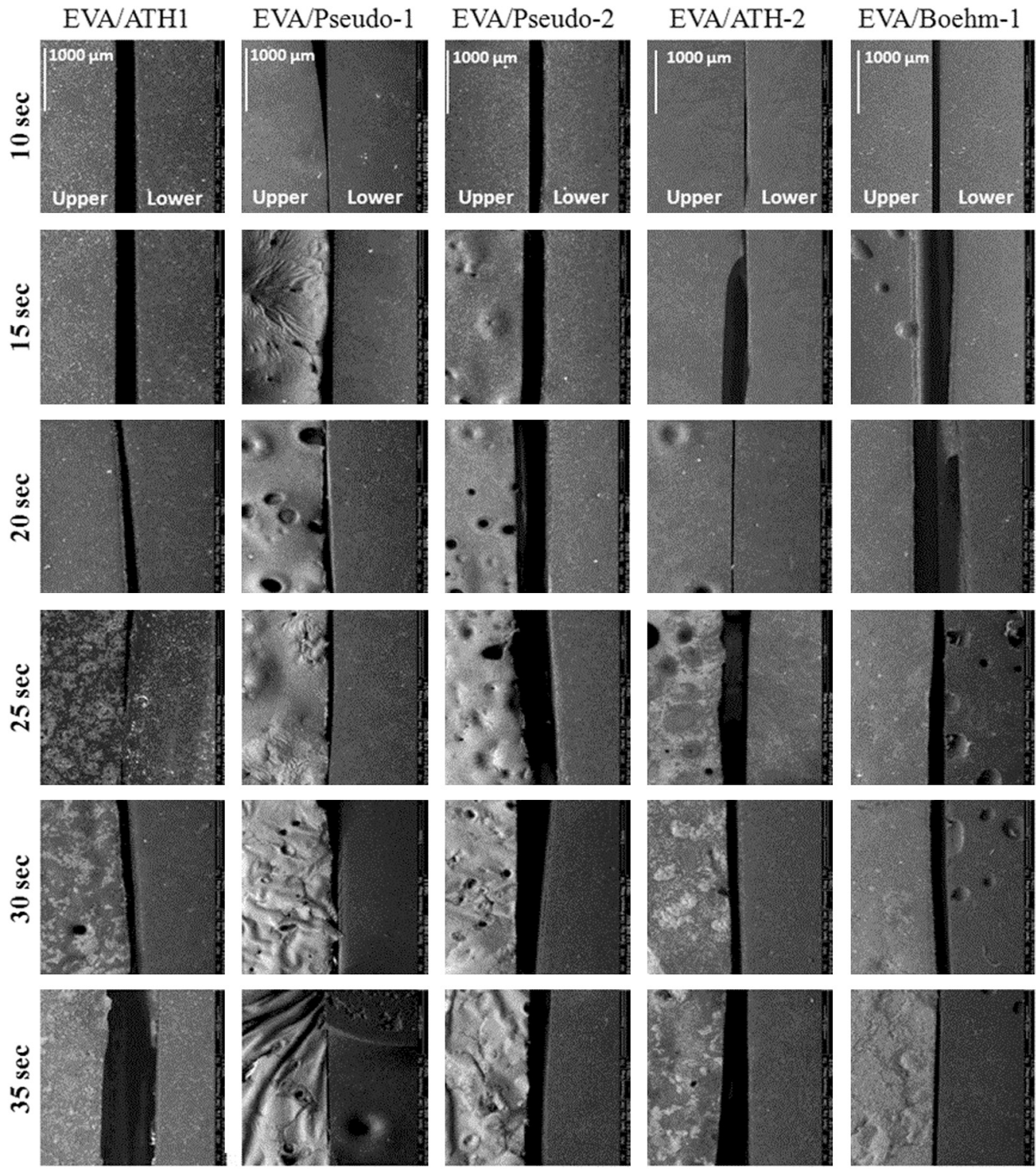

Fig. 10. ESEM micrographs $(100 \times)$ of upper and lower area of EVA composites at different exposure times. 
containing Pseudo-2. This observation highlights a very fast mineral layer formation in presence of these two pseudoboehmites. At $25 \mathrm{~s}$, we observe that the surface is more enriched with fillers in presence of Boehm-1, Pseudo-1 and Pseudo-2. The formation of a non-homogeneous crust is detected in presence of ATH-1 and ATH2 after $25 \mathrm{~s}$ of exposure. For higher exposure time (30 and $35 \mathrm{~s}$ ) the creasing of the formed crust is observed. This observation is correlated to the EVA flow that repels the fillers from the surface. It is remarkable to note that the formed crust remains cohesive in presence of Pseudo-1 and Pseudo-2 even after EVA melting at 30 and $35 \mathrm{~s}$.

ESEM observations performed at very high magnification $(\times 4000)$ on the specimens centre are presented Fig. 11. Low surface enrichment is observed in presence of ATH-1 at $20 \mathrm{~s}$. At $25 \mathrm{~s}$ the formation of a highly heterogeneous surface crust (particle aggregates) is observed. It is obvious that the EVA melting upon heat exposure leads to fillers dispersion and separation resulting in an unprotected surface. Same behavior is detected in the presence of ATH-2. In presence of Boehm-1 gradual surface fillers enrichment starts from 25 s. Fillers dispersion is observed for higher exposure time and it seems that boehmite particles have a poor ability to link together. Outstanding evolution is detected in presence of Pseudo-1 and Pseudo-2. Fillers enrichment and rearrangement are observed after $15 \mathrm{~s}$ in presence of Pseudo-1. A mineral film is developed on the upper surface at $20 \mathrm{~s}$ in presence of both pseudoboehmites. At 30 and $35 \mathrm{~s}$ a highly cohesive crust with strong interaction and bonding between the fillers is observed. These observations support our hypothesis regarding the improvement of the fire behavior of EVA in the presence of Pseudo-1 and Pseudo-2 through the formation of a cohesive insulating layer which promotes an efficient barrier effect. As said above, specific orientation of these fillers, as well as additional phenomena like agglomeration, may explain the high cohesion of the crust which contributes to the efficient barrier effect.

Moreover, such a fast formation of a mineral layer on the upper surface can be explained by fillers migration in addition to polymer ablation. Fillers enrichment on the upper surface was quantitatively evaluated by elemental analysis using EDX. The evolution of the
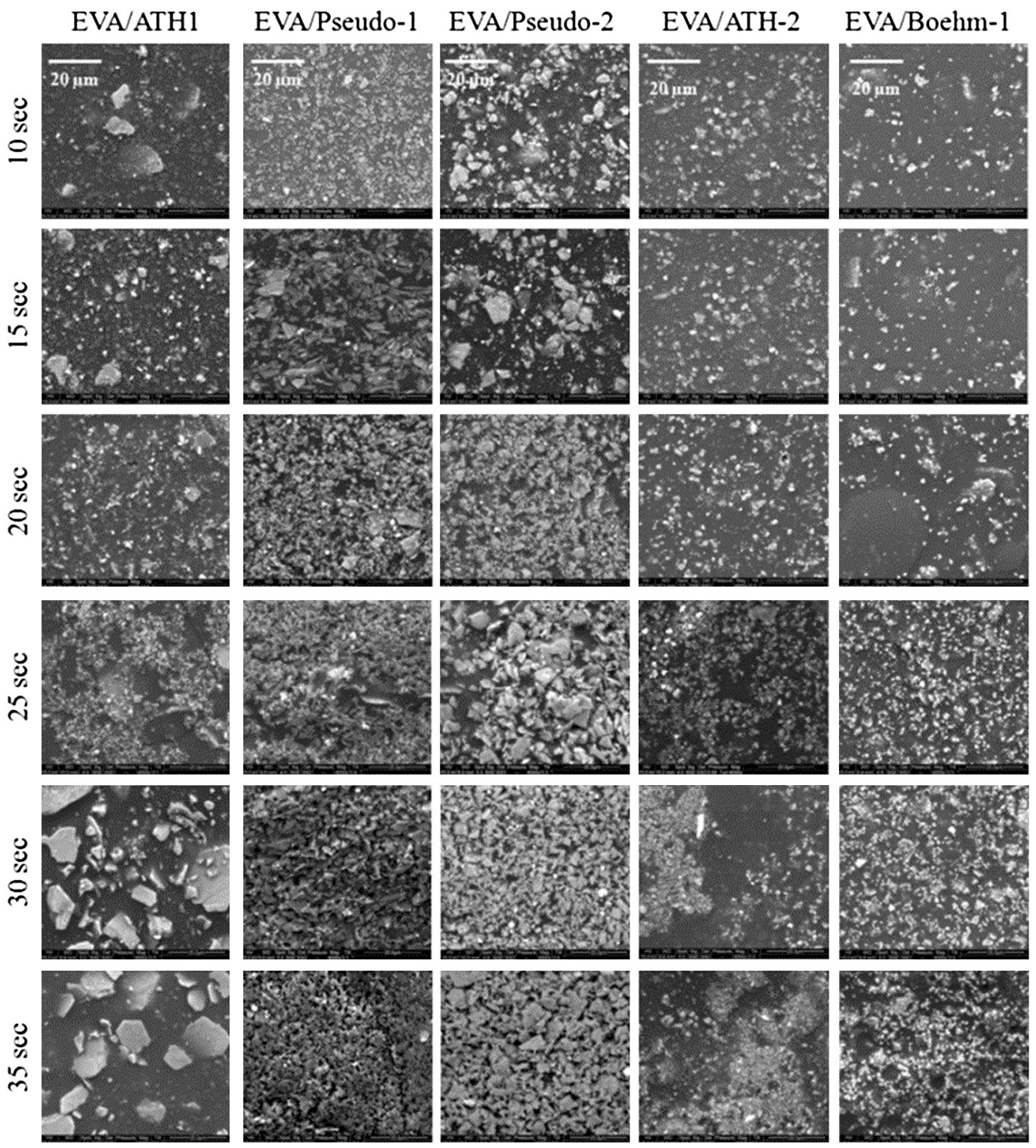

Fig. 11. ESEM micrographs $(4000 \times)$ of upper area of EVA composites at different exposure times. 

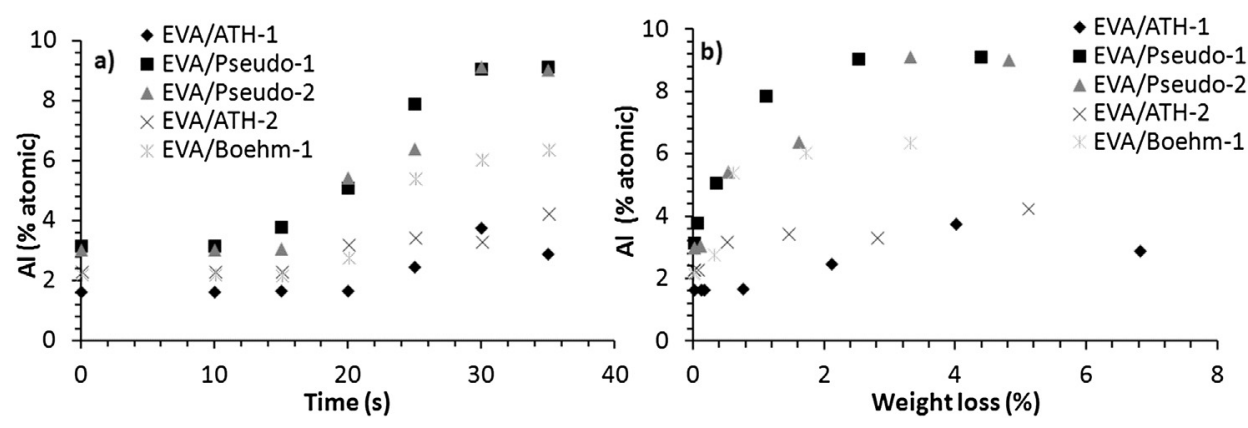

Fig. 12. Atomic percentage of aluminum for upper area of EVA composites versus a) exposure time and b) weight loss.

atomic percentage of aluminum element on the upper surface for all the composites is plotted versus time and weight loss in Fig. 12-a and - $b$ respectively. In presence of ATH-1, the aluminum percentage remains stable until $20 \mathrm{~s}$ of exposure. We notice a slight increase at $25 \mathrm{~s}$. A maximum is reached around $30 \mathrm{~s}$ before decreasing at $35 \mathrm{~s}$. This behavior is in agreement with the ESEM observations carried out on the upper surface and is correlated to fillers drive away from the surface caused by the EVA melting. For EVA containing $25 \%$ of ATH-2 a slight increase followed by a fast stagnation of the aluminum element percentage at $20 \mathrm{~s}$ is observed. In presence of boehmite the aluminum percentage remains constant until $20 \mathrm{~s}$. A slight increase followed by a stagnation of the aluminum element percentage is detected from $25 \mathrm{~s}$. On the other side, in presence of Pseudo-1 and Pseudo-2, the aluminum element percentage increases steadily from 15 to $20 \mathrm{~s}$ respectively. This increase is very fast and takes place while the weight loss variation remains very low as observed in Fig. 12-b. It is obvious that the surface enrichment with the aluminum fillers is not only related to weight loss neither to polymer ablation. For identical mass loss the enrichment of aluminum fillers is much more important in presence of pseudoboehmites. For example, at $25 \mathrm{~s}$ the weight loss of EVA composites is similar (about $2 \%, 1.1 \%$ and $1.5 \%$ in presence of ATH-1, Pseudo- 1 and Pseudo- 2 respectively) but the aluminum percentage increases three times (relative to starting values) in presence of Pseudo-1 and Pseudo-2 compared to an increase of one time in presence of ATH-1. These observations confirm the fast fillers migration and accumulation of pseudoboehmites which promote the formation of a superficial insulating layer leading to an effective barrier effect. The ability of pseudo-boehmites to migrate to the surface was supposed to be related to their shape (lamellar), their high aspect ratio $(L / t=14-17)$ and their preferential orientation after processing. Other mechanisms like bubbling can also promote a fast enrichment in fillers. Nevertheless, such enrichment should be quite heterogeneous at least at the beginning. On the contrary, in the case of Pseudo-1 and Pseudo-2, the enrichment is very homogeneous. Therefore, migration appears to be the most relevant phenomenon.

\section{Conclusion}

This paper reports the flame retardancy of EVA filled with $25 \mathrm{wt} . \%$ of different aluminum hydroxide mineral fillers. The study focused on the understanding of the EVA fire properties improvement observed in cone calorimeter tests. Pseudoboehmites exhibit greater flame-retardant properties in comparison to aluminum trihydroxydes and boehmite by promoting significant reduction in pHRR values. This significant improvement is related neither to a modification of the melt viscosity, nor to the fillers endothermic effect nor to an increase in EVA thermal stability. Using the PCFC analysis in combination to the cone calorimeter analysis, the barrier effect was identified as the predominant factor responsible for this improvement. Thereafter, the ESEM observations and EDX analyses have clearly shown that this effective barrier effect observed in presence of the pseudoboehmites is mainly caused by a fast formation of a cohesive and homogeneous insulating layer at the surface of the composites. Such formation is believed to be due to an outstanding migration phenomenon within few seconds after heat exposure in addition to polymer ablation. Other phenomena, as orientation of fillers and agglomeration, may also contribute to the high cohesion of the mineral layer.

\section{Acknowledgments}

The authors gratefully acknowledge ACOME and Toyal Europe companies for supplying all the materials used in this work and for their financial support.

\section{References}

[1] Cho C-W, Shin S-C. Enhanced transversal delivery of atenolol from the ethylene-vinyl acetate matrix. Int J Pharm 2004;287:67-71.

[2] Cardelli A, Ruggeri G, Calderisi M, Lednev O, Cardelli C, Tombari E. Adhesion and rheological properties of EVA-based hot-melt adhesives. Int J Adhes Adhes 2006;26:571-6.

[3] Sonia A, Priya Dasan K. Celluloses microfibers (CMF)/poly (ethylene-co-vinyl acetate) (EVA) composites for food packaging applications: a study based on barrier and biodegradation behavior. J Food Eng 2013;118:78-89.

[4] Delfosse L, Baillet C, Brault A, Brault D. Combustion of ethylene-vinyl acetate copolymer filled with aluminum and magnesium hydroxides. Polym Degrad Stab 1989;23:337-47.

[5] Covaci A, Harrad S, Abdallah MA-E, Ali N, Law RJ, Herzke D, et al. Nove brominated flame retardants: a review of their analysis, environmental fate and behavior. Environ Int 2011;37:532-56.

[6] Watanabe I, Sakai S. Environmental release and behavior of brominated flame-retardants-an overview. Organohalog Compd 2001;52:1-4.

[7] Alaee M. Arias P, Sjodin A, Bergman A. An overview of commercially used brominated flame retardants, their applications, their use patterns in different countries/regions and possible modes of release. Environ Int 2003;29:683-9.

[8] Persistent Organic Pollutants Review Committee, Intersessional work on hexabromocyclododecane, Geneva, 15-19 October 2012. http://chm.pops.int/ Convention/POPsReviewCommittee/LatestMeeting/POPRC8/tabid/2809/mctl/ ViewDetails/EventModID/871/EventID/230/xmid/9095/Default.aspx.

[9] Durin-France A, Ferry L, Lopez Cuesta J-M, Crespy A. Magnesium hydroxide zinc borate/talc compositions as flame-retardants in EVA copolymer. Polym Int 2000;49:1101-5.

[10] Hull R, Price D, Liu Y, Wills CL, Brady J. An investigation into the decomposition and burning behaviour of ethylene-vinyl acetate copolymer nanocomposite materials. Polym Degrad Stab 2003;82:365-71.

[11] Costache MC, Jiang DD, Wilkie CA. Thermal degradation of ethylene-vinyl acetate copolymer nanocomposites. Polymer 2005;46:6947-58.

[12] Monti M, Camino G. Thermal and combustion behavior of polyethersulfoneboehmite nanocomposites. Polym Degrad Stab 2013;98:1838-46.

[13] Pawlowski KH, Schartel B. Flame retardancy mechanisms of aryl phosphates in combination with boehmite in bisphenol A polycarbonate/acrylonitrilebutadiene-styrene blends. Polym Degrad Stab 2008;93:657-67.

[14] Zhang J, Ji Q, Zhang P, Xia Y, Kong Q. Thermal stabilityand flame-retardancy mechanism of poly(ethylene terephthalate)/boehmite nanocomposites. Polym Degrad Stab 2010;95:1211-8.

[15] Laachachi A, Ferriol M, Cochez M, Lopez-Cuesta J-M, Ruch D. A comparison of the role of boehmite $(\mathrm{AlOOH})$ and alumina (Al2O3) in thethermal stability and 
flammability of poly(methyl methacrylate). Polym Degrad Stab 2009;94: 1373-8.

[16] Friederich B, Laachachi A, Sonnier R, Ferriol M, Cochez M, Toniazzo V, et al. Comparison of alumina and boehmite in (APP/MPP/metal oxide) ternary systems on the thermal and fire behavior of PMMA. Polym Adv Techno 2012;23:1369-80.

[17] Cai Y, Zhao M, Wang H, Li Y, Zhao Z. Synthesis and properties of flameretardant poly(vinyl alcohol)/pseudo-boehmite nanocomposites with high transparency and enhanced refractive index. Polym Degrad Stab 2014;99: 53-60.

[18] McGarry K, Zilberman J, Hull RT, Woolley DW. Decomposition and combustion of EVA and LDPE alone and when fire retarded with ATH. Polym Int 2000;49(10):1193-8.

[19] Hull RT, Witkowski A, Hollingbery L. Fire retardant action of mineral fillers. Polym Degrad Stab 2011;96:1462-9.

[20] Quach Y, Cinausero N, Sonnier R, Longuet C, Lopez-Cuesta J-M. Barrier effect of flame retardant systems in poly(methyl methacrylate): study of the efficiency of the surface treatment by octylsilane of silica nanoparticles in combination with phosphorous fire retardant additives. Fire Mater 2012;36(7):590-602.

[21] Tang Y, Lewin M. Migration and surface modification in polypropylene (PP)/ polyhedral oligomeric silsequioxane (POSS) nanocomposites. Polym Adv Technol 2009;20:1-15.

[22] Schartel B, Weib A, Sturm H, Kleemeier M, Hartwig A, Vogt C, et al. Layered silicate epoxy nanocomposites: formation of the inorganic-carbonaceous fire protection layer. Polym Adv Technol 2011;22:1581-92.

[23] Sturm H, Schartel B, Weib A, Braun U. SEM/EDX: advanced investigation of structured fire residues and residue formation. Polym Test 2012;31:606-19.

[24] Tang Y, Lewin M, Pearce EM. Effects of annealing on the migration behavior of PA6/Clay nanocomposites macromol. Rapid Commun 2006;27:1545-9.

[25] Hao J, Lewin M, Wilkie CA, Wang J. Additional evidence for the migration of clay upon heating of clay-polypropylene nanocomposites from X-ray photoelectron spectroscopy (XPS). Polym Degrad Stab 2006;91:2482-5.

[26] Isitman NA, Dogan M, Bayramli E, Kaynak C. The role of nanoparticle geometry in flame retardancy of polylactide nanocomposites containing aluminium phosphinate. Polym Degrad Stab 2012;97:1285-96.
[27] Pastor HO, Frache A, Boccaleri E, Marchese L, Camino G. Heat induced structure modifications in polymer-layered silicate nanocomposites. Macromol Mater Eng 2004;289:783-6.

[28] Lewin M. Some comments on the modes of action of nanoparticules in the flame retandancy of polymers. Fire Mater 2003;27:1-7.

[29] Huang N, Lewin M, Tang Y, Fan C, Wang J. Studies on the migration in PA6OMMT nanocomposites: effect of annealing on migration as evidenced by ARXPS (angle resolved X-ray photoelectron spectroscopy). Polym Adv Technol 2008;19:993-1001.

[30] Tang Y, Lewin L. Maleated polypropylene OMMT nanocomposite: annealing, structural changes, exfoliated and migration. Polym Degrad Stab 2007;92:53-60.

[31] Tang Y, Lewin M. New aspects of migration and flame retardancy in polymer nanocomposites. Polym Degrad Stab 2008;93:1986-95.

[32] Camino G, Maffezzoli A, Braglia M, De Lazzaro M, Zammarano M. Effect of hydroxides and hydroxycarbonate structure on fire retardant effectiveness and mechanical properties in ethylene-vinyl acetate copolymer. Polym Degrad Stab 2001;74:457-64.

[33] Fitzgerald JJ, Piedra G, Dec SF, Seger M, Maciel GE. Dehydration studies of a high-surface-area alumina (Pseudo-boehmite) using solid-state $1 \mathrm{H}$ and $27 \mathrm{Al}$ NMR. Am Chem Soc 1997:119:7832.

[34] Cai W, Li $\mathrm{H}$, Zhang Y. Influences of processing techniques of the $\mathrm{H}_{2} \mathrm{O}_{2}$ precipitated pseudoboehmite on the structural and textural properties of $\gamma$ $\mathrm{Al}_{2} \mathrm{O}_{3}$. Colloids Surf A Physicochem Eng Asp 2007;295:185-92.

[35] Shi Y, Kashiwagi T, Walters RN, Gilman JW, Lyon RE, Sogah DY. Ethylene vinyl acetate/layered silicate nanocomposites prepared by a surfactant-free method: enhanced flame retardant and mechanical properties. Polymer 2009;50:3478-87.

[36] Sonnier R, Ferry L, Longuet C, Laoutid F, Friederich B, Laachachic A, et al. Combining cone calorimeter and PCFC to determine the mode of action of flame-retardant additives. Polym Adv Technol 2011;22:1091-9.

[37] Kashiwagi T, Mu M, Winey K, Cipriano B, Raghavan SR, Pack S, et al. Relation between the viscoelastic and flammability properties of polymer nanocomposites. Polymer 2008;49:4358-68.

[38] Kashiwagi T, Shields JR, Harris RH, Davis RD. Flame-retardant mechanism of silica: effects of resin molecular weight. J Appl Polym Sci 2003;87:1541-53. 